\title{
Rebeldes y revolucionarias: aportes a la antropología feminista (1970-1992)
}

\author{
Marisa Ruiz Trejo' \\ 'Universidad Autónoma de Chiapas, México
}

\section{Resumen}

La antropología feminista ha conformado un campo de conocimiento dentro de la disciplina desde una perspectiva de género. Actualmente existen escasos trabajos sobre el desarrollo de las antropologías feministas locales, por lo que en este trabajo me intereso por recuperar la vida y obra de algunas pensadoras importantes para la antropología feminista, a las que me refiero como rebeldes y revolucionarias. Me centro en el desarrollo de este campo epistémico en Chiapas y Centroamérica, entre los años setenta y noventa (s. XX), periodo marcado por la convulsión política, la represión, las políticas de contrainsurgencia en la región, lo que afectó fuertemente a estudiantes y profesoras de la época, algunas organizadas en los movimientos revolucionarios centroamericanos. Me enfoco específicamente en los aportes de Alaíde Foppa, Stella Quan, Walda Barrios y Marta Casaús y analizo no solamente su quehacer antropológico y sociocientífico sobre las críticas feministas marxistas y socialistas a las nociones tradicionales de clase, las influencias del pensamiento gramscicano, los cuestionamientos anticoloniales de la época que marcaron su pensamiento, sino también sus experiencias políticas en movimientos sociales y revolucionarios, así como algunas de sus vivencias personales.

Palabras clave: feminismo marxista, socialismo, pensamiento gramsciano, anticolonialismo, antropología feminista. 


\title{
Rebel and revolutionary women: \\ contributions to feminist anthropology (1970-1992)
}

\begin{abstract}
Feminist anthropology has built a field of knowledge within the discipline from a gender perspective. Currently, there are few works on the development of local feminist anthropologies. For that reason, in this work, I am interested in recovering the life and work of some important thinkers for feminist anthropology which I refer as rebels and revolutionaries. I focus on the development of this subfield in Chiapas and Central America, between the 1970 and 1990 (2oth century), a period marked by political conflicts, repression, and counterinsurgency policies, which strongly affected students and teachers of the time, some of them organized in the Central American revolutionary movements. I focus specifically on the contributions of Alaíde Foppa, Stella Quan, Walda Barrios, and Marta Casaús and I analyze not only their anthropological and socio-scientific work about Marxist and socialist feminist critiques of traditional notions of class, the influences of Gramscian thought, the anti-colonial questions that marked their thinking, but also their political experiences in social and revolutionary movements, as well as some of their personal experiences.
\end{abstract}

Keywords: Marxist feminism, socialism, Gramscian thought, anti-colonialism, feminist anthropology.

\section{Rebeldes e Revolucionárias: contribuições para a antropologia feminista (1970-1992)}

\section{Resumo}

A antropologia feminista construiu um campo de conhecimento dentro da disciplina a partir da perspectiva de gênero. Atualmente, existem poucos trabalhos sobre o desenvolvimento de antropologias feministas locais. Por isso, neste trabalho, estou interessada em resgatar a vida e a obra de algumas importantes pensadoras da antropologia feminista que chamo de rebeldes e revolucionárias. Concentro-me no desenvolvimento deste subcampo em Chiapas e na América Central, entre as décadas de 1970 e 1990 (século XX), um período marcado por conflitos políticos, repressão e políticas de contra-insurgência, que afetaram fortemente estudantes e professores da época, algumas delas organizadas nos movimentos revolucionários da América Central. Concentro-me especificamente nas contribuições de Alaíde Foppa, Stella Quan, Walda Barrios e Marta Casaús e analiso não apenas seus trabalhos antropológicos e socio-científicos sobre as críticas feministas marxistas e socialistas às noções tradicionais de classe, as influências do pensamento gramsciano, as questões anticoloniais que marcaram seu pensamento, mas também suas experiências políticas nos movimentos sociais e revolucionários, bem como algumas de suas experiências pessoais.

Palavras-chave: feminismo marxista, socialismo, pensamento gramsciano, anticolonialismo, antropologia feminista. 


\title{
Rebeldes y revolucionarias: aportes a la antropología feminista (1970-1992)
}

\author{
Marisa Ruiz Trejo
}

\section{Introducción}

La antropología feminista ha conformado un campo de conocimiento dentro de la disciplina desde una perspectiva de género, al introducir conceptos elementales como androcentrismo, etnocentrismo y clasismo. El desarrollo de este campo epistémico ha tenido distintos devenires en contextos como el de Estados Unidos, Francia, América Latina y el Caribe (Castañeda, 2015). En Chiapas y Centroamérica, como parte de una misma región, se han producido trabajos elaborados por mujeres y feministas con particularidades y puntos de enunciación que los distinguen de aquellos producidos en otras regiones.

Recuperar las memorias de antropólogas, investigadoras y pensadoras pioneras en esta región ha sido uno de mis intereses investigativos de los últimos años. Así, he mostrado cómo desde las primeras mujeres en este campo se hicieron aportes a los análisis sobre la situación de las mujeres y cómo las pioneras no siempre dejaron de reproducir etnocentrismo y formas clásicas de hacer antropología. Los heterogéneos y múltiples aportes de las mujeres y feministas a las Ciencias Sociales y Humanidades, particularmente a la antropología en Chiapas y Centroamérica, desde principios del siglo XX hasta la actualidad, se pueden dividir en varias etapas: desde los aportes de las pioneras de la antropología (1930-1964); la participación de pensadoras feministas marxistas, anticoloniales y gramscianas en contextos de represión en Centroamérica (1964-1989); así como investigaciones de antropólogas feministas, indígenas, afrodescendientes y LGTB+ de las nuevas generaciones con diferentes desafíos (1990-2020). En mi investigación, he analizado con mayor profundidad algunas de las particularidades de cada uno de los periodos mencionados (Ruiz-Trejo 2016, 2020a, 2022).

En este artículo, pretendo centrarme en la influencia de las críticas feministas al marxismo, así como el pensamiento gramsciano y anticolonial en los trabajos de algunas antropólogas y pensadoras de Chiapas y Centroamérica, entre los años setenta y noventa (s. XX), a quienes identifico como mujeres rebeldes y revolucionarias. Este periodo estuvo marcado fuertemente por un desarrollo histórico desigual, conflictos agrarios ocasionados por la acumulación de la tierra en manos de grandes terratenientes, lucha de clases, conflictos armados, movimientos revolucionarios, así como el genocidio en Guatemala, causado por militares guatemaltecos, que a principios de la década de los ochenta (s. XX), produjo que más de ochenta mil personas, en su mayoría campesinos mayas, se refugiaran en Chiapas.

La convulsión política de la época implicó que estudiantes y profesoras fueran amenazadas, perseguidas, encarceladas, humilladas, asesinadas y que algunas huyeran al exilio por la represión y las políticas de contrainsurgencia de estados dictatoriales centroamericanos. Dicho periodo también tuvo la particularidad de que fue el momento en que, según Castañeda (2012), la teoría feminista y la perspectiva de género se incorporaron dentro de la antropología crítica. 
Por esto, en este artículo, recupero los trabajos de Alaíde Foppa (1914-1980), Stella Quan Rossell (1935-2007), Walda Barrios-Klee (1951-2021) y Marta Casaús Arzú (1948) y analizo las influencias que marcaron su quehacer antropológico y sociocientífico. Además, otras antropólogas destacadas de este periodo son: Mercedes Olivera (1934), Aura Marina Arriola (1937-2007), Myrna Mack (1940-199o), Yolanda Aguilar (1963), entre otras'. No obstante, por límites en la extensión, en este trabajo me referiré solamente a algunas.

Si bien no todas las investigadoras seleccionadas en este artículo fueron antropólogas, sus investigaciones se vieron influenciadas por prácticas y recursos de la antropología social ${ }^{2}$ y algunas participaron en grupos de antropólogas, historiadoras y académicas organizadas de la época. Se preocuparon por la situación y los problemas de las mujeres indígenas, campesinas y mestizo-ladinas y algunas fueron militantes en los movimientos revolucionarios y socialistas. Fueron profesoras de universidades centroamericanas y mexicanas y vivieron una época en la que las publicaciones académicas y periodísticas incluían mayoritariamente a autores y escasamente aparecían trabajos de autoras. Así también en la antropología, en los congresos y en los movimientos sociales se tomaba como punto de referencia la voz de los varones, centrándose exclusivamente en su palabra y su experiencia.

Todas ellas se enfrentaron a contextos adversos, a la persecución política y a la violencia sexual sistemática y genocida. La impronta en antropología feminista de Alaíde Foppa, escritora de origen guatemalteco, se debe fundamentalmente a que fue una de las pioneras en los estudios de género y feministas en México y Centroamérica. Alaíde Foppa, Stella Quan y Walda Barrios estuvieron exiliadas en México y, a su vez, se vincularon con los movimientos de mujeres indígenas y campesinas e integraron las primeras generaciones de profesoras en el campo. Formaron a varias generaciones de estudiantes de distintas disciplinas de las Ciencias Sociales y de las Humanidades. Alaíde Foppa y Marta Casaús comparten varios aspectos: su formación intelectual, su extracción de clase y el hecho de cuestionar su propia clase económica3. Stella Quan y Alaíde Foppa comparten el hecho de que sus trabajos estuvieron orientados a la literatura, género significativo para la antropología. Ambas escribían en la Revista Fem que fue importante para su trayectoria, no solamente porque Alaíde fue su fundadora, sino porque fue un espacio en donde ambas tejieron profundas relaciones políticas, intelectuales y de amistad con otras mujeres mexicanas y de otros países latinoamericanos.

Algunas de las pensadoras seleccionadas para este trabajo apoyaron los movimientos revolucionarios y los movimientos sociales de la época. Así documentaron, registraron y denunciaron la explotación de las mujeres en el sistema capitalista, el racismo que las élites dominantes, así como las masacres, desapariciones, asesinatos $y$ violencias infringidas por los estados dictatoriales centroamericanos y acompañaron los procesos de denuncia judicial y psicoterapéuticos y de sanación de las víctimas y sobrevivientes del conflicto armado interno en Guatemala.

Para la realización de esta investigación, realicé trabajo de campo y entrevistas semiestructuradas a varias mujeres significativas para las Ciencias Sociales en la región, entre 2016 y 2020, tanto en San Cristóbal de las Casas, Chiapas, México, como en Ciudad de Guatemala, Guatemala. En las entrevistas, indagué sobre la relación de sus trayectorias académicas con los procesos políticos y sociales de sus lugares de origen y sobre sus experiencias familiares y personales. Además, hice búsquedas en la biblioteca y archivo de la Asociación para el Avance de las Ciencias Sociales en Guatemala (AVANCSO), en el archivo del Centro de investigaciones regionales de Mesoamérica (CIRMA), así como en el Archivo Histórico del Feminismo en México del Centro de Investigaciones y Estudios de Género (CIEG-UNAM). Asimismo, a través de un archivo familiar propio,

\footnotetext{
Ver Ruiz-Trejo (2020a) y (2020b) en donde he abordado los trabajos de algunas de estas antropólogas.

Es necesario destacar que las carreras de antropología en las universidades centroamericanas no fueron creadas hasta la década de los noventa.

Esto también fue un rasgo distintivo de Rosario Castellanos, escritora chiapaneca, cuyos trabajos tuvieron presencia en antropología.
} 
he revisado de manera física artículos publicados en algunos números de las revistas Ojarasca, Fem, Observador de la frontera sur, Perfil del Sureste, Antzetik, así como Revista de la USAC, en donde escribieron las autoras mencionadas y en donde encontré información relevante sobre la historia centroamericana y chiapaneca, entre finales de los años setenta y mediados de los noventa (s. XX). También mantuve un intercambio epistolar por email con Yosahandi Navarrete, hija de Stella Quan.

Es indispensable señalar que en este artículo existen tres ejes temáticos y analíticos con los que se organizó la información recogida: 1) la relación entre la producción de conocimiento y las condiciones históricas, las redes de parentesco, las influencias intelectuales, políticas, así como los orígenes étnicos y de clase de las antropólogas; 2) la introducción de las mujeres y el feminismo en la agenda de la investigación antropológica, así como 3) la selección de los temas, la manera de construir y concebir el "objeto de investigación”, de hacer trabajo de campo, las herramientas y las prácticas de investigación.

Cabe destacar que este trabajo no es un esfuerzo individual, sino que es fruto de un trabajo colectivo que se ha enriquecido a través de los aportes del grupo independiente "Las del Fondo", conformado por Martha Patricia Castañeda Salgado, Mary Goldsmith, Lina Rosa Berrio Palomo, Monserrat Salas Valenzuela, Laura R. Valladares y Marisa Ruiz-Trejo, quienes somos integrantes del Colegio de Etnólogos y Antropólogos Sociales A.C. (CEAS). Al interior del CEAS, formamos la Comisión de Antropología Feminista y de Género, que ha impulsado una serie de actividades académicas como: seminarios, conversatorios, paneles en congresos mexicanos e internacionales, presentaciones de nuestro libro sobre "Antropologías feministas en México: epistemologías, éticas, prácticas y miradas diversas" (Berrio et al., 2020), entre otros eventos, que nos han permitido recuperar las trayectorias de vida y teorizaciones de las antropólogas feministas en América Latina, estudiar viejos y nuevos temas antropológicos desde una mirada teórica y metodológica feminista, así como enlazar y construir proyectos comunes con otras antropólogas latinoamericanas. Todo esto ha enriquecido fuertemente mis análisis y reflexiones ${ }^{4}$.

\section{Críticas feministas marxistas y socialistas}

El materialismo fue una de las corrientes antropológicas clásicas con intensos debates en el campo de la antropología de las mujeres de los años setenta, posteriormente denominada antropología del género y antropología feminista, desarrollada principalmente a partir de la década de los ochenta y los noventa (s. $\mathrm{XX}$ ). La crítica feminista en antropología contribuyó a las relecturas marxistas que reelaboraron las nociones de producción y reproducción, esta última entendida como la reproducción de la mano de obra. Algunas propuestas entendieron la división generalizada del trabajo como base de la subordinación de las mujeres 5 . Otras posturas propusieron que "las mujeres constituyen una clase social" y otras rechazaron estos postulados al señalar que las mujeres se encuentran representadas en todas las clases sociales.

\footnotetext{
4 Actualmente hemos conformado la Red Mexicana de Antropólogas Feministas, en coordinación con antropólogas de otros países latinoamericanos, y hemos propuesto el Grupo de Trabajo de Antropologías Feministas, que será coordinado por Martha Patricia Castañeda Salgado, en el marco de la Asociación Latinoamericana de Antropología (ALA), lo que augura un fortalecimiento de los lazos existentes.

5 Tanto la obra de Karl Marx, sobre los modos de producción y la formación de clases sociales, como la Friedrich Engels, sobre La familia, la propiedad privada y el estado (1884) influyeron fuertemente en la antropología del género y la antropología feminista. Según Aurelia Martín Casares (2006), "las teorías marxistas han propugnado formas de organización de tipo comunista-comunitarios- para frenar el avance del capitalismo. Este nuevo tipo de sociedad estaría caracterizado por la libertad y la desaparición de la explotación de los trabajadores. Friedrich Engels, que trabajó muy directamente sobre las relaciones sociales de género, pensaba que los roles de hombres y mujeres evolucionarían hacia el igualitarismo con el avance de las relaciones de producción hacia la nueva sociedad socialista en la que la explotación de las mujeres desaparecería completamente. Según sus presupuestos, las razones de la mayor explotación de las mujeres estaban directamente vinculadas al paso de la propiedad comunal a la propiedad privada” (2006:172).
} 
Las categorías de género, los factores económicos y las condiciones materiales son parte de las perspectivas de investigación antropológica de la década de los setenta y ochenta. Las teorías, conceptos y temáticas son numerosos, pero sin duda una apreciación bastante común de la época era que las teorías marxistas se equivocaban al pensar en la subordinación de género como subsumida en la división de clases. Estos debates influyeron en algunas de las pensadoras del periodo analizado, sobre todo, a partir de 1975, cuando se realizóla Conferencia sobre la Mujer en ciudad de México y la Organización de las Naciones Unidas (ONU) declaró dicha época como el "Año Internacional de la Mujer"6. A dicha conferencia, asistieron socialistas y Alaíde Foppa tuvo un papel importante en la divulgación de dichos debates a través del programa radiofónico "Foro de la Mujer".

\section{Pensamiento gramsciano y anticolonial}

Los procesos de descolonización de África y Asia entre los años cuarenta y sesenta, impactaron en las discusiones de la disciplina a través de las obras de autores de las excolonias que se trasladaron a las exmetropolis. Los trabajos Aimé Césaire, Frantz Fanon, Édouard Glissant, Albert Memmi, y el pensamiento de Antonio Gramsci, filósofo marxista italiano, entre otros pensadores, circularon por América Latina y el Caribe, en la década de los setenta y ochenta, lo que contribuyó al desarrollo de un pensamiento anticolonialista propio.

Las relecturas de los conceptos gramscianos sobre ideología, hegemonía cultural, clase dominante, clases subalternas, intelectuales orgánicos, entre otros términos, inspiraron varios trabajos investigativos. Tanto las ideas marxistas, el pensamiento anticolonialista como el pensamiento gramsciano fueron también fuente de inspiración de los movimientos revolucionarios centroamericanos, así como puntos de partida para las críticas de género y feministas en antropología, tal como veremos a continuación.

\section{Alaíde Foppa y el salario para el trabajo doméstico}

Recuperar el trabajo de Alaíde Foppa es un asunto obligado para reconstruir la especialidad que hoy denominamos antropología feminista. Alaíde Foppa, escritora y creadora, nacida en Barcelona en 1914, quien vivió una gran parte de su vida en Guatemala y luego estuvo exiliada en México en los años cincuenta, influyó con sus escritos y sus denuncias sobre varias generaciones de antropólogas 7 . Fue la creadora de la primera cátedra de sociología de la mujer en la Facultad de Ciencias Políticas y Sociales, de la Universidad Nacional Autónoma de México (UNAM); del programa radial "Foro de la Mujer", que se transmitió con su voz a través de Radio Universidad desde 1972 hasta 1980, y de Fem, una de las primeras revistas feministas en México con gran repercusión en América Latina. El trabajo de Alaíde incidió tanto en los escritos de antropólogas y pensadoras contemporáneas de su tiempo como en las generaciones posteriores. De hecho, los artículos publicados por ella en la revista Fem son fuente inagotable de información sobre las teorías, conceptos y debates de la época en la que vivió.

Alaíde Foppa era doctora en Letras Italianas, lo que posiblemente produjo que en algunos de sus artículos mostrara influencias del feminismo italiano, aunque también del feminismo socialista estadounidense, y sus críticas a los limitados análisis marxistas de clase. En su célebre artículo “¿Salario para el trabajo doméstico?”,

\footnotetext{
6 Ese año también se conmemoró por primera vez el Día Internacional de la Mujer, en conmemoración a las 129 costureras que murieron en un incendio durante una huelga en Washington Square, Nueva York, al ser encerradas por los dueños de la fábrica para que estas no se unieran al paro.

7 En el marco del IV Congreso Mexicano de Antropología Social y Etnología, organizado por el Colegio de Etnólogos y Antropólogos Sociales A.C. (CEAS), realizado en Querétaro, en 2016, impulsamos entre varias actividades, un taller sobre antropología feminista en México, en el que pedimos a las asistentes de varias generaciones (1940-2016), identificar en una línea del tiempo a las antropólogas y los libros que influyeron en sus trabajos. Algo interesante es que el nombre de Alaíde Foppa, así como la fundación de la revista Fem, fueron plasmados como parte de la genealogía de la antropología feminista en México.
} 
publicado en la Revista Fem en 1977, Alaíde Foppa citó a las feministas marxistas italianas, al Grupo Lotta Feminista, a Giuliana Pompei, a Mariarosa Dalla Costa, a Nora Federici y al Colectivo Internacional Feminista de Italia ${ }^{8}$; pero también a Isabel Larguía ${ }^{9}$, comunista argentina (1932-1988) y a su compañero John Dumoulin, antropólogo de formación marxista, implicados ambos en la lucha armada revolucionaria rural en Cuba, y a quienes posiblemente conoció en persona.

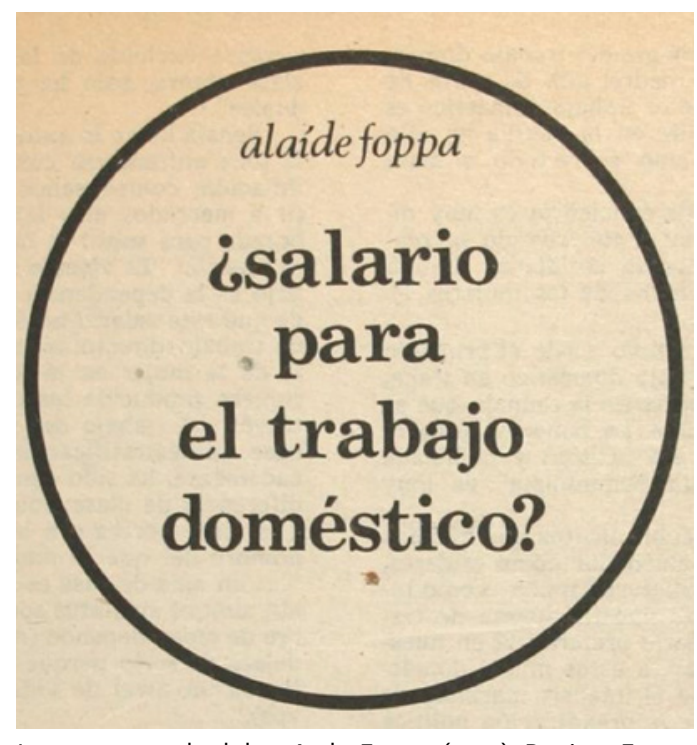

Imagen tomada del artículo Foppa (1977). Revista Fem.

Foppa (1977) leyó el libro El Poder de La Mujer y La Subversión de La Comunidad (1975), de Mariarosa Dalla Costa y Selma James, feminista socialista estadounidense internacionalista, un libro clave sobre el trabajo doméstico y sobre cómo en la relación de las mujeres con el capital es fundamental producir y reproducir la fuerza de trabajo de la que depende el sistema capitalista. La utilización de autoras italianas, francesas, estadounidenses y latinoamericanas por Foppa (1977) confirma un punto importante sobre la teorización feminista mexicana y centroamericana, debido a que no ha tenido un origen único y vernáculo, sino constantes intercambios, importaciones, traducciones y diálogos con las teorías e ideas feministas de otros contextos.

En el mismo artículo, Foppa (1977) recuperó algunas de las críticas a los análisis tradicionales de clase que no contemplaron la fuerza de trabajo producida y reproducida por las mujeres y aquellas discusiones que han cuestionado por qué el trabajo doméstico no es considerado como un trabajo productivo y quién debería de pagar por esto que se considera como un "no-trabajo".

La misma autora dominaba el francés, debido a que pasó una temporada en París, en donde nacieron dos de sus hijos. Posiblemente su conocimiento sobre los trabajos de Evelyne Soullerot sobre la historia y la sociología del trabajo femenino provengan de esa experiencia. El artículo de Foppa sobre el salario para el trabajo doméstico (1977) es un texto muy completo de las discusiones de la época sobre la plusvalía o las ganancias para los varones y para el empresariado que el trabajo de las mujeres ha generado en muchas unidades "domésticas", así como la reposición de la fuerza de trabajo del obrero que es como el feminismo marxista llama al hecho de que las mujeres vivan para reproducirse y parir.

8 Este colectivo estuvo integrado por Mariarosa Dalla Costa, Selma James, Silvia Federici, entre otras, tres autoras que han influido fuertemente en los análisis antropológicos sobre la reproducción, el capitalismo y el trabajo asalariado.

9 Isabel Larguía también estuvo implicada en el Frente Sandinista de Liberación Nacional (FSLN) de Nicaragua, en donde estuvo encarcelada. Uno de sus grandes aportes desde una perspectiva feminista fue el trabajo "Por un feminismo científico" que publicó con Dumoulin y "Hacia una ciencia por la liberación de la mujer" (Larguía y Dumoulin 1976). 
Alaíde Foppa provenía de una familia acomodada, pero su posición siempre estuvo a la izquierda. Junto con Alfonso Solórzano, su esposo, tuvieron una trayectoria que demostró su compromiso con los derechos democráticos en América Latina. El 19 de diciembre de 1980, Alaíde Foppa viajó desde México a Guatemala donde fue detenida, secuestrada y luego desaparecida junto a Leocadio Actún Shiroy, el conductor que la llevaba. Ambos fueron retenidos por el servicio de inteligencia G-2 del ejército de Guatemala, durante el gobierno de Romeo Lucas García ${ }^{10}$.

La noticia sobre la desaparición de Alaíde Foppa fue contundente y desde aquel momento hasta el día de hoy, su caso aún no ha sido esclarecido. La violación sistemática de los derechos humanos, las desapariciones y la represión que vivió Guatemala tanto en el periodo de Lucas García, como en el posterior gobierno de facto de Efraín Ríos Montt, nos muestran que la desaparición de Alaíde Foppa no fue un caso aislado, sino uno de los tantos de la época, como táctica contra el movimiento popular, profesores y profesoras, estudiantes, entre otros actores sociales.

Sobre Alaíde Foppa se han escrito cientos de líneas y pronunciamientos. Decenas de organizaciones y organismos internacionales de Derechos Humanos de la ONU y de la OEA se han solidarizado por la causa exigiendo su paradero con vida. Sin duda, el vacío que Alaíde Foppa dejó es un dolor latente que desde lejos nos muestra cómo hasta en el exilio, las angustias del pueblo de Guatemala no terminaron. Sus programas radiofónicos del "Foro de la Mujer" son una línea abierta de investigación para entender otros debates de la época que han tenido impacto en la antropología feminista en México, como las discusiones sobre familia, aborto, maternidad voluntaria, huelgas de obreras, justicia, encuentros de mujeres, feminismos, igualdad, desarrollo, entre otros.

\section{Stella Quan Rossell: entre antropología y activismo feminista en los procesos revolucionarios}

Stella de la Luz Quan Rossell (1935-2007) fue una antropóloga guatemalteca, exiliada en México"1. Se casó con el antropólogo Carlos Navarrete, con quien tuvo dos hijos y de quien se divorció más tarde. Navarrete estuvo exiliado en México debido a su participación en las manifestaciones estudiantiles antigubernamentales y anti-imperialistas en Guatemala, entre marzo y abril de 1962, durante el gobierno del general Miguel Ydígoras Fuentes (1958-1963) ${ }^{12}$. Stella Quan fue una de las mujeres que se trasladó a México para encontrarse con su pareja. Stella ingresó con visa de estudiante y al llegar a México se autodefinió como exiliada y se quedó de manera permanente. Así, Stella vivió su experiencia universitaria en el exilio, hizo la carrera de etnología en la Escuela Nacional de Antropología e Historia (ENAH), a la que ingresó dos meses después de su llegada. Posteriormente se incorporó como profesora en el Programa Universitario de Estudios de Género (Rodríguez de Ita, 2020).

Yosahandi Navarrete, Doctora en Literatura por el Colegio de Morelos e hija de Stella, me compartió lo siguiente sobre su madre:

"el divorcio fue un motor para la autoafirmación de mi madre y su participación cada vez más activa en el feminismo. Tomó talleres, cursos, participó en encuentros y debates. Escribió cuentos y relatos sobre sus experiencias de vida. Así, dejó de ser "la esposa de Carlos Navarrete", figura influyente de la antropología, para reafirmarse como Stella

\footnotetext{
10 Esta información fue brindada por el Frente Democrático Contra la Represión en Guatemala (FDCR), según la Revista Fem (1980, p. 3).

11 Agradezco a Mary Goldsmith quien me habló por primera vez de Stella Quan y quien realizó un relevante trabajo sobre las pioneras en antropología en la época de oro (Goldsmith y Sánchez, 2014).

12 Según Rodríguez de Ita (2020), durante la gestión ydigorista, integrantes de diversos sectores sociales, optaron por las armas. Así explicó: “Uno de los primeros levantamientos, que se verificó el 13 de noviembre de 1960, estuvo encabezado por un grupo de jóvenes nacionalistas del ejército descontentos con el gobierno debido a que éste había facilitado el adiestramiento en territorio guatemalteco de mercenarios contrarios a la revolución cubana; luego se dieron otros levantamientos más. De allí surgieron los primeros grupos guerrilleros, como el Movimiento Revolucionario 13 de Noviembre (MR-13) y más tarde, en 1962, las llamadas Fuerzas Armadas Rebeldes (FAR), con vocación antigubernamental y antiimperialista, a cuyas filas se incorporaron muchos jóvenes" (Rodríguez de Ita 2020: s/p). Para la misma autora, las políticas de contrainsurgencia y la represión de estado produjeron la salida forzada, documentada o indocumentada, de militantes y simpatizantes de las movilizaciones y de los grupos guerrilleros.
} 
Quan Rossell. No fue fortuito, pienso, que poco después de su separación comenzó su activismo por Guatemala” (Comunicación personal con Yosahandi Navarrete Quan, 4 de septiembre de 2021).

Algunos de los títulos de los artículos de Stella Quan, publicados en la revista Fem, nos dan una idea de sus intereses en el periodo seleccionado para el análisis: “Mi refugio eran las lágrimas': confiesa una feminista salvadoreña” (1977); “Nicaragua: estrenando libertad” (1980); "Por la vida de la compañera Alaíde Foppa” (1981); "Esta noche esta carta, Alaíde" (1982) y "Ser mujer refugiada latinoamericana” (1986).

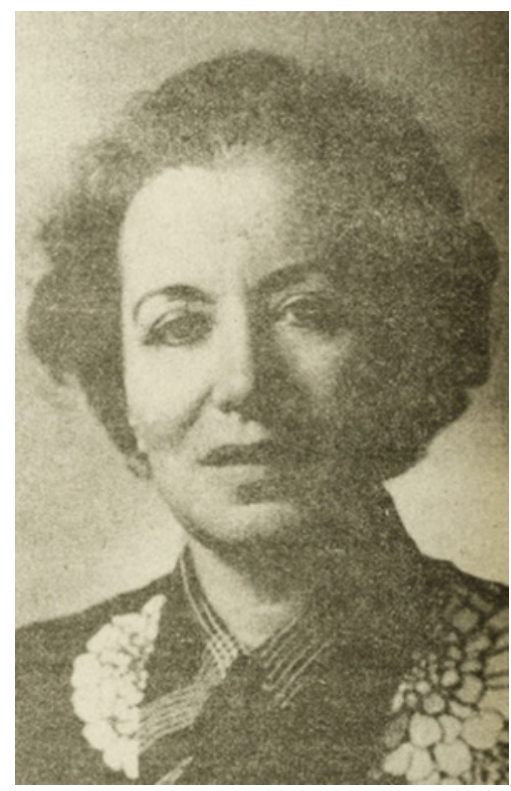

Alaíde Foppa, en Quan, Stella (1982).

Por su manera de referirse a Alaíde Foppa en sus textos es evidente que Stella tenía un gran aprecio por la escritora feminista. Según Quan (1981), Foppa y ella se encontraron una vez en Costa Rica, a donde Stella había ido por un congreso. Charlaron sobre noticias de sus hijos y comieron comida china. Este dato no es menos importante, ya que, al ordenar, Alaíde mencionó: "tu eres la china, tú escoges”, por lo que es posible que el origen del apellido "Quan”, no tan común en Guatemala, tenía ascendencia china'3.

Por otro lado, la foto que el Comité Internacional por la vida de Alaíde Foppa difundió, nos revela algunas de las experiencias de Alaíde, pero también algunos de los intereses investigativos y personales de Stella, quien escribió las siguientes líneas en el artículo “Esta noche esta carta, Alaíde” (1982):

Extraña foto la que el Comité internacional por tu vida ha seleccionado para la prensa, para enviar a sus filiales de Europa, de Canadá... Extraña foto, Alaíde... la que tomó y me regaló Graciela Iturbide es bellísima porque eres tú y tu casa, tú y tu sonrisa; tú y la mesita donde se colocaban las cafeteras, las teteras, los pasteles de Lita. Tu y la mesita rodante de tu estudio, tú con tus collares indígenas del altiplano guatemalteco, tú y tu sonrisa.

Esta en cambio es extraña, extraña para todos nosotros porque no sonríes, no vemos tu expresión de picardía, de complicidad (el viento corrió la cortina y tiró tu foto), de alegría, de ganas y coraje ante la vida y de valor y capacidad de sublimación ante la muerte. Es bella, sin embargo, estas triste Alaíde; como dijera Berta consternada: "Aquí seguramente ya había muerto Alfonso"; aquí seguramente ya decías: "Me faltan un ojo y una pierna, pero veo y camino."

13 Cabe señalar que la migración china a Chiapas y Centroamérica fue muy importante a principios de siglo XX, por lo que ha dejado una huella cultural, culinaria y artística. 
Sí, Alaíde, aquí seguramente ya estás amputada, cercenada. ¡Qué gran dignidad, cuánto de tu vida, de tu belleza - externa e interna- se rescata en ella!, en los periódicos, sin embargo, pese a ser la misma foto, por las sombras, se te ve sonriendo. ¡Extraña foto, Alaíde, extraña foto!. (Quan 1982: 54).

En ese texto, Quan se refiere a cómo la muerte de Alfonso Solórzano, esposo de Foppa, había afectado fuertemente a la escritora. Por otro lado, Juan Pablo Solorzano Foppa ${ }^{14}$, su hijo más pequeño, integrante del Ejército Guerrillero de los Pobres (EGP) fue perseguido, capturado y desaparecido el 7 de junio de 1980 en el municipio de Nebaj, departamento de Quiché, por integrantes del Ejército de Guatemala (Solórzano, 2021) (5, $^{15}$ lo que probablemente entristeció y angustió a Alaíde.

Stella Quan también le dedicó otro texto titulado “Por la vida de la compañera Alaíde Foppa” (1981), publicado en la misma revista, en el que señaló que Alaíde era la única persona que podía "darle órdenes" y de quién absurdamente las recibía y las hacía rebeldemente y gruñendo, lo que junto con otras anécdotas, demuestra la cercanía y complicidad que tuvieron estas dos pensadoras.

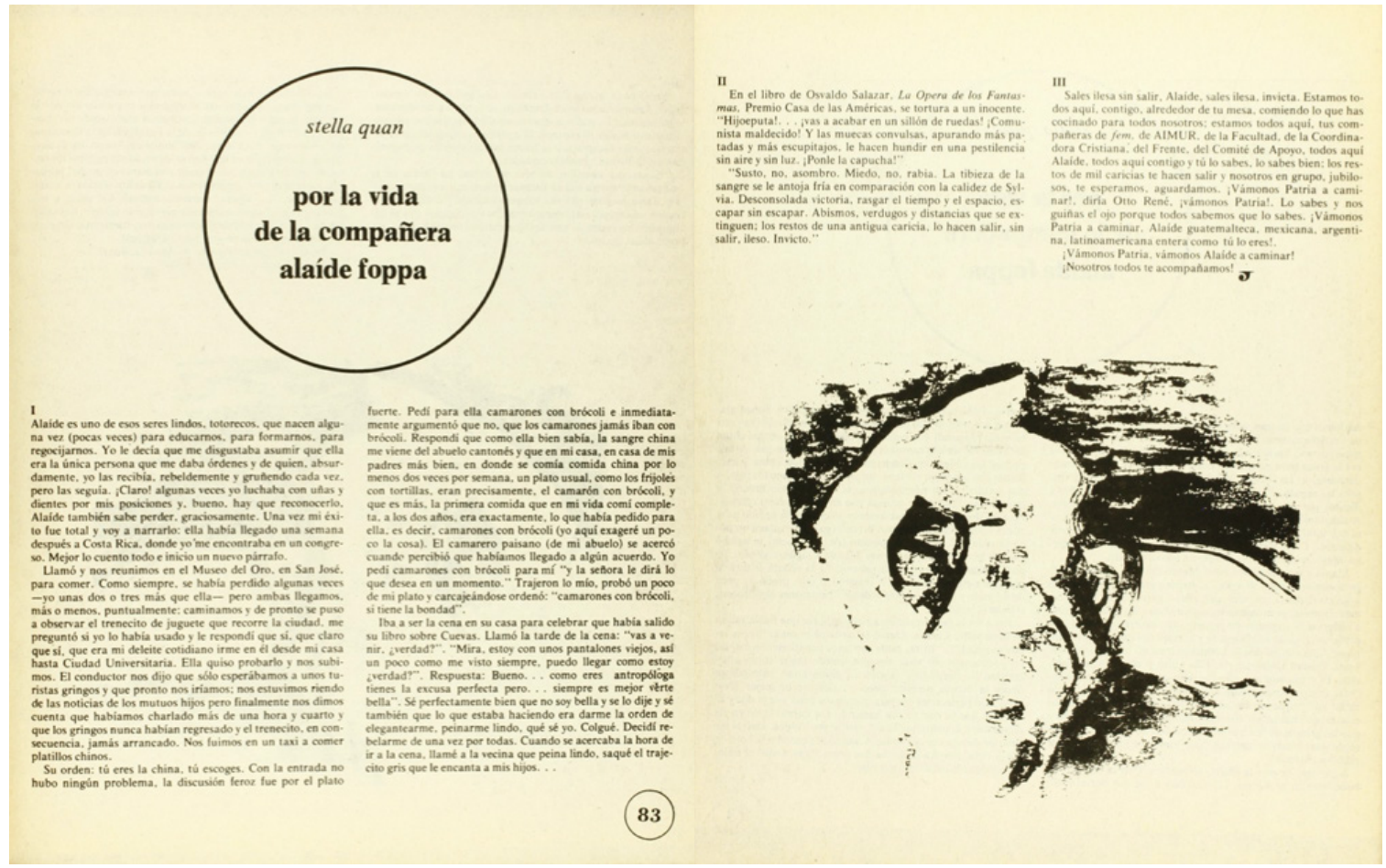

Quan, Stella (1981). Por la vida de la compañera Alaíde Foppa. Revista Fem, volumen IV, no 17, febrero-marzo, p. $83-85$

Yosahandi Navarrete (2020) ha hecho un trabajo de recuperación de los escritos de su madre. En un artículo titulado "Alaíde Foppa y AIMUR, o una voz que emerge en medio de las llamas", publicado en GaZeta, Yosahandi Navarrete (2020) explica los esfuerzos de Stella Quan y de Alaíde Foppa en la creación de la Asociación Internacional de Mujeres contra la Represión en Guatemala (AIMUR) y expone la experiencia de ambas como defensoras de los derechos de las mujeres.

14 Utilizaba el seudónimo de Cristóbal/Esteban.

15 Al respecto, Julio Solórzano Foppa (2021) el hijo mayor de Alaíde Foppa, explicó: "Mis hermanos Mario, Silvia y Juan Pablo se incorporaron a la lucha revolucionaria en los años 70 y fueron integrantes del Ejército Guerrillero de los Pobres-EGP. Juan Pablo, el menor de mis hermanos murió en Nebaj, Quiché, en un enfrentamiento con el ejército en junio de 1980; su cuerpo no ha sido encontrado, al igual que el cuerpo de Mario, quien murió en la Ciudad de Guatemala un año después, en junio de 1981, también en un enfrentamiento con fuerzas de seguridad. Afortunadamente, Silvia sobrevivió y vive actualmente en Guatemala; Laura, nuestra otra hermana, vive en Ecuador". 
En esa misma línea, en el programa radiofónico número 54 de "Foro de la mujer"16, Alaíde mantuvo un diálogo con Stella Quan. Esta última explicó cómo algunas antropólogas e historiadoras se organizaron a partir de la quema y la masacre de la embajada de España en ciudad de Guatemala, el 31 de enero de 1980, para reunir material sobre la situación de violencia vivida en Guatemala, particularmente contra las mujeres, así como para realizar denuncias y divulgación nacional e internacional sobre la convulsa situación política en Centroamérica. Debido a la indignación por las treinta y siete personas asesinadas en la embajada, entre ellas cinco mujeres mayas-quichés. AIMUR fue fundada dos días después de este trágico evento.

AIMUR ofreció apoyo al Frente Democrático contra la Represión en Guatemala (FDCR), organismo legal creado en febrero de 1979, que representaba a más de 150 agrupaciones de oposición democrática al interior de Guatemala. AIMUR contribuyó con lo que las antropólogas e historiadoras sabían hacer: investigar sobre la situación de las mujeres y brindar asistencia y acompañamiento a víctimas de violencia y violación sexual. AIMUR es un ejemplo de los primeros grupos de antropólogas organizadas a finales de la década de los setenta en México, un dato relevante para las genealogías de la antropología feminista mexicana y centroamericana que ilustra cómo las antropólogas han utilizado las herramientas de documentación y registro de la disciplina para protestar, organizarse y manifestarse en contra de la represión. Así también el programa "Foro de la mujer" es un ejemplo del uso de medios de comunicación como la radio por antropólogas feministas, para denunciar las urgencias sociales en distintas épocas.

Por otro lado, Stella Quan se interesó por recopilar historias de vida de cómo y cuál fue el impacto de la guerra, los conflictos políticos y sociales, en la vida cotidiana, y en la parte más íntima de las personas en Guatemala. De hecho, recientemente la editorial “Catafixia”, publicó una trilogía o “Tríptico de la Revolución”, de Stella Quan Rossell, publicación dirigida por Luis Méndez Salinas y Carmen Lucía Alvarado, y editada por Yosahandi Navarrete, en donde dan a conocer los trabajos realizados por Stella sobre el proceso revolucionario en Guatemala de 1944-1954; un periodo particular que inició con la "Revolución de Octubre" o la "Revolución de Guatemala de 1944", cuando un movimiento cívico militar derrocó a Jorge Ubico y, más tarde, llevó al poder a Jacobo Árbenz, quien fue acusado de comunista, por afectar los intereses de los monopolios estadounidenses como la United Fruit Company y los oligopolios agrícolas nacionales, a través de la conocida Reforma Agraria de Guatemala. El movimiento revolucionario en Guatemala se dio a partir de 1954 cuando se derrocó al gobierno electo de Jacobo Árbenz, mediante un Golpe de Estado, ejecutado por un sector del ejército con apoyo de empresarios locales, internacionales y con el Gobierno de los Estados Unidos. La selección de los temas de Stella Quan y sus búsquedas nos muestran su interés investigativo por los movimientos sociales y revolucionarios en Guatemala.

Los libros publicados por Catafixia recopilan historias de vida de artistas, políticos y escritores y se centran en el impacto de la guerra y en los conflictos políticos y sociales en Guatemala (Quan, 2018a, 2018b, 2018c). Antes de ser publicados, dichos trabajos le sirvieron a Stella para obtener el título de etnóloga y el grado de maestra en Ciencias Antropológicas en la Escuela Nacional de Antropología e Historia en México (ENAH), con la tesis titulada "Guatemala: una cultura de la ignominia. Siete biografías y una entrevista" (1972), bajo la dirección de Guillermo Bonfil Batalla, con lo que contribuyó a revelar la larga memoria de la guerra.

En su tesis, Stella Quan se centró en los testimonios de Jacobo Rodríguez Padilla, Alfonso Solórzano y Luis Cardoza y Aragón, entre otros, a quienes entrevistó. Así hoy podemos ver el libro No es el fin, es el mar. (Crónica y voces de Luis Cardoza y Aragón), ${ }^{17}$ en el que Stella Quan presenta a este escritor y poeta guatemalteco exiliado

16 Este programa se encuentra almacenado en el Sistema Digital de Almacenamiento Masivo de Radio UNAM y existe una copia en la Fonoteca Nacional, ubicado en Coyoacán.

17 Además, el libro La Escuela Nacional de Bellas Artes y los escritores y artistas del 44: Jacobo Rodríguez Padilla: una historia de vida (QUAN, 2018) nos introduce a los recuerdos de este pintor, grabador y escultor guatemalteco. En 1950, Rodríguez Padilla fue becado por el Ministerio de Educación de Guatemala para formarse en Francia, no obstante, su beca se suspendió con el derrocamiento de Árbenz. El libro recupera nombres, momentos y lugares de la Guatemala de la Revolución. También da cuenta del dramático golpe que sufrieron los artistas e intelectuales al momento de ser intervenidos por la contrarrevolución y 
en México, quien tuvo que huir tras el derrocamiento de Árbenz, con Lya Kostakowky, su esposa, y con quien Stella fundó AIMUR (Navarrete, 2020). En la época de Romeo Lucas García, Luis Cardoza y Aragón denunció las violaciones a los Derechos Humanos en Guatemala junto a Tito Monterroso, Mario Monteforte Toledo ${ }^{18}$, Alaíde Foppa y otros intelectuales guatemaltecos en el exilio, lo que posiblemente le costó la vida a Alaíde al viajar a Guatemala (Solórzano 2021).

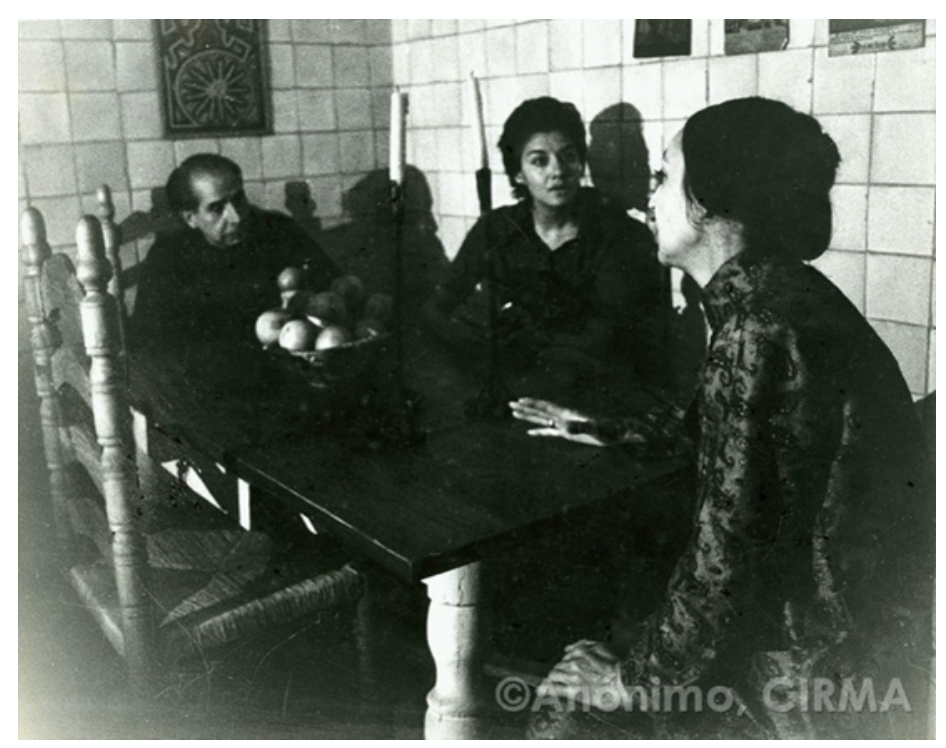

Luis Cardoza y Aragón, su esposa Lya Kostakowsky y Stella Quan Rossell en su casa en Coyoacán, México. De octubre de 1968 a abril de 1970. Fototeca Guatemala. Colección de Roberto Díaz Castillo sobre Luis Cardoza y Aragón. Centro de Investigación.

En algunas fotografías del archivo del Centro de Investigaciones Regionales de Mesoamérica (CIRMA), se ve a Stella Quan junto a Luis Cardoza y Aragón en su casa de Coyoacán, durante las múltiples visitas hechas por la antropóloga para realizar las entrevistas y construir su testimonio. En las fotos, Stella parece estar muy interesada en la conversación con la pareja y en una actitud de escucha activa. Estas fotografías documentan los múltiples encuentros que Stella Quan tuvo con Cardoza y Aragón para construir su testimonio.

Los tres libros de Stella Quan, publicados por Catafixia, resultan importantes para la genealogía de la antropología feminista. Se trata de trabajos realizados entre 1968 y 1972, una época en la que la presencia de las mujeres en la disciplina aún era aún escasa. La antropóloga guatemalteca recopiló materiales testimoniales sobre la lucha permanente en Guatemala; la represión, la violencia, el acoso, las muertes y el dolor, pero también la resistencia, la alegría y la esperanza ${ }^{19}$. Además, su trabajo antropológico resulta importante debido a que

de sus larguísimas consecuencias. Por otro parte, en el libro La semilla que yo sembré: Alfonso Solórzano: testimonio (Guatemala, 1911-México, 1980), [Stella Quan (2018b) nos muestra toda una época en Guatemala, a través del testimonio de Solórzano, una figura central en la época revolucionaria guatemalteca. La voz de Solórzano nos aclara el contexto en que se dio la Reforma Agraria en Guatemala, la conformación del Partido Comunista guatemalteco, desde Árbenz hasta el proceso revolucionario en la década de los sesenta, cuando distintos sectores de la población se organizaron contra la represión generalizada y en el campo miles de víctimas fueron masacradas, con más de doscientas mil víctimas, en su mayoría población indígena maya. Alfonso Solórzano, esposo de Alaíde Foppa, quedó en un segundo plano debido a la prioridad que tuvo la obra de la escritora feminista y víctima revolucionaria y el hecho de que Stella Quan haya recuperado sus aportes es un ejercicio importante de memoria para la familia Solórzano-Foppa, cuya historia es representativa de las condiciones en que los y las intelectuales de la época desarrollaron sus trabajos y activismos políticos.

18 Augusto Monterroso fue un escritor hondureño, nacionalizado guatemalteco y exiliado en México. Formó parte de la llamada generación de mascarones. Mario Monteforte Toledo era un escritor guatemalteco y obtuvo el Premio Nacional de Literatura “Miguel Ángel Asturias” en Guatemala.

19 En el programa radiofónico de “Foro de la Mujer” (Radio UNAM, número 8), a propósito del Encuentro Internacional de la Mujer de 1975, Alaíde Foppa mencionó que dicho encuentro fue algo particular debido a que por primera vez había una representación de mujeres en cada una de las delegaciones. Así explicó: "si se tratara de un congreso de antropología, de medicina o de ciencias sociales, las mujeres representarían una muy pequeña minoría, por lo que es necesario que haya un congreso de mujeres para que todos los países sean representados por mujeres y para que las mujeres constituyan obviamente la mayoría". 
se trata de una guatemalteca exiliada que realizó investigación sobre otros exiliados y exiliadas en México, lo que le permitió tener una comprensión más amplia y profunda, al haber pasado por experiencias similares a las que se enfrentaron sus entrevistados.

Cabe destacar que Quan utilizó un modelo metodológico tradicional y riguroso para la recopilación de los siete testimonios de su tesis, en los que no grabó a sus entrevistados y nunca estuvo "frente a frente" de ellos, sino junto a ellos. Así escuchó con cuidado, tomó notas, no interrumpió y "trató de borrarse del texto" (Méndez, 2018). Esto nos sirve para pensar cómo han ido cambiando no sólo los temas seleccionados, sino las propuestas metodológicas. Las mujeres involucradas en la disciplina marcaron un momento paradigmático por el hecho de ser las primeras generaciones de etnógrafas.

Por último, cabe destacar la asesoría de Stella Quan como antropóloga en la película "El norte", dirigida por Gregory Nava (Estados Unidos, Reino Unido, 1983), así como su participación como parte del elenco. Dicha película trata de un hermano y una hermana que huyen de la persecución en su hogar en Guatemala y viajan al norte, a través de México y luego a los Estados Unidos, con el sueño de comenzar una nueva vida, historia entrelazada con su propia biografía.

Quedan muchas líneas de investigación abiertas sobre la vida de Stella antes de su exilio en México, su colaboración con el PIEM y el PUEG, su trabajo desarrollado en el Centro Eucuménico con mujeres exiliadas centroamericanas, su publicación sobre Guatemala en Sisterhood is Global (Quan, 1984), sus publicaciones en El Fígaro de Guatemala y en el Unomásuno de México, así como sus reflexiones autobiográficas sobre la importancia de su formación como antropóloga para su quehacer como activista, temas que pueden ser horizontes para futuras publicaciones.

\section{Walda Barrios y la situación de las mujeres en el socialismo}

Walda Barrios-Klee nació en la ciudad de Guatemala el 8 de septiembre de 1951 y falleció recientemente el 28 de abril de 2021. Fue heredera de una tradición de lucha revolucionaria socialista, pero también de intereses por los derechos de las mujeres, ya que su madre y su padre estuvieron implicados en distintas luchas políticas. Walda Barrios se identificó como socialista.

Su madre fue la primera licenciada en Pedagogía de Guatemala y su padre colaboró en el gobierno de Jacobo Árbenz. Walda solía señalar que utilizaba los apellidos Barrios-Klee para reivindicar la memoria de su padre, funcionario de la Reforma Agraria, y de su tío, Hugo Barrios Klee, asesinado en la década de los setenta (s. XX), ambos luchadores sociales. Debido al contexto político guatemalteco, Walda se desplazó a México en dos ocasiones. La primera vez el 9 de septiembre de 1957 como asilada, cuando era apenas una niña, con un salvoconducto en el mismo avión donde iba expulsado el presidente Árbenz, junto con otros funcionarios del gobierno revolucionario, entre ellos su padre (Mosquera, 2021).

A finales de la década de los cincuenta regresó a Guatemala. Estudió magisterio y se graduó de maestra de primaria. Ingresó a la Licenciatura en Ciencias Jurídicas y Sociales y se tituló de abogada y notaria en 1976. No obstante, ella misma se consideraba más antropóloga que abogada porque - como decía - "es lo que he hecho en mi vida”, por lo que se articuló con las redes de antropólogas feministas latinoamericanas (Ruiz-Trejo y Ramazzini, 2021). Estudió la maestría en sociología rural en la Pontificia Universidad Católica del Ecuador. Se graduó en el año de 1978 y regresó como docente a la Universidad de San Carlos de Guatemala, época de represión contra el movimiento estudiantil, popular y campesino. 


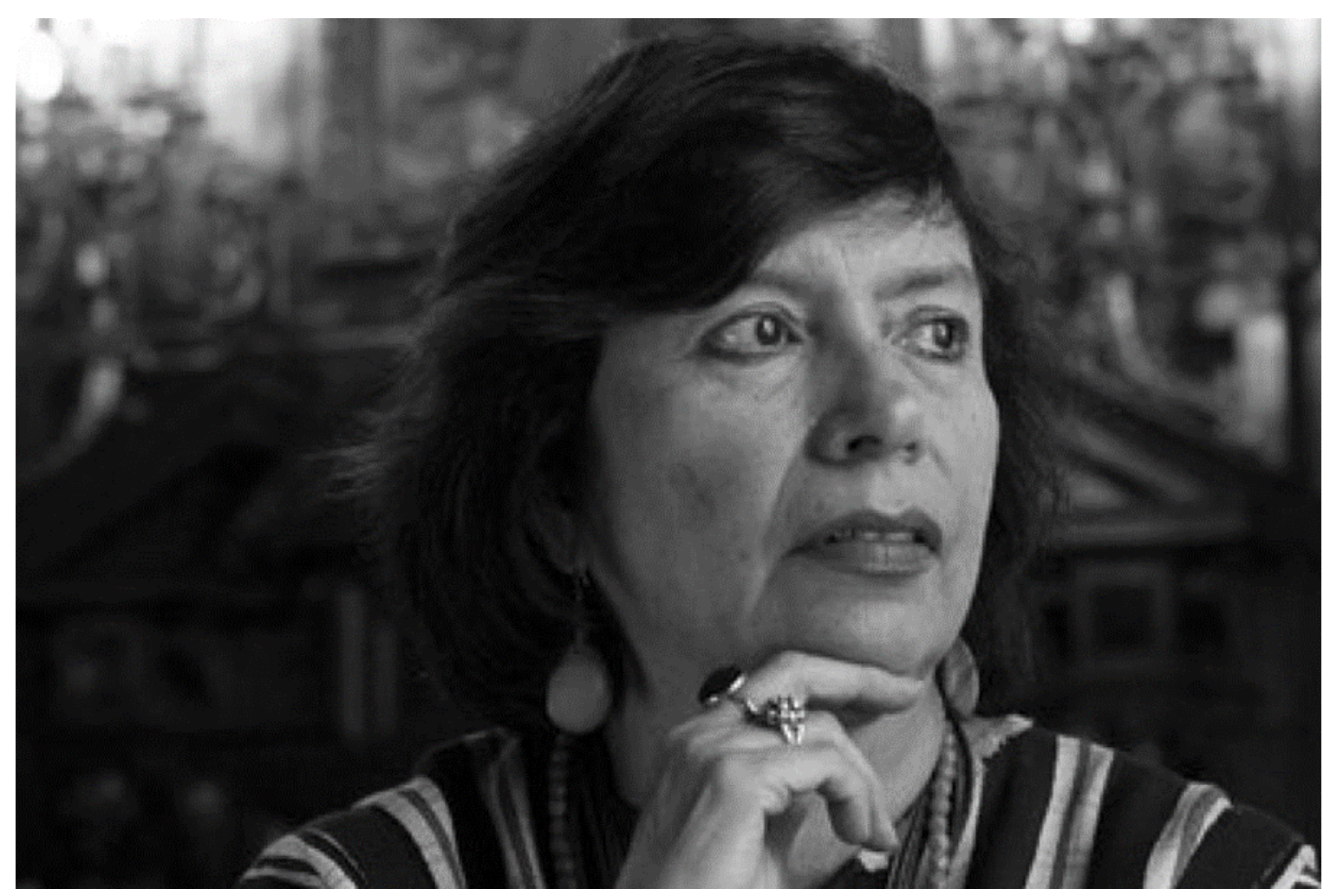

Foto Walda Barrios Klee

Su segundo desplazamiento a México fue en los años ochenta, cuando salió exiliada de Guatemala, junto a su pareja Antonio Mosquera y obtuvo el carácter de refugiada debido a la persecución política de aquel momento. En Chiapas, ambos se instalaron en San Cristóbal de las Casas, en donde fueron profesores de las carreras de antropología y sociología de la Universidad Autónoma de Chiapas. Walda fue conocida por su papel como mentora, académica e iniciadora de los estudios de género y feministas en Chiapas (Ruiz-Trejo, 2021). En la década de los ochenta, Walda se dedicó a la investigación durante ese periodo terrible para Centroamérica, debido a las políticas de contrainsurgencia del Estado guatemalteco que produjeron secuestros, desapariciones, asesinatos, masacres y el genocidio en Guatemala, por lo que miles de refugiadas y refugiados, entre ellos estudiantes y profesores como Walda y su esposo, huyeron y se establecieron en Chiapas. Walda estuvo muy pendiente de los campamentos de refugiados y mostró siempre su solidaridad, particularmente con las mujeres indígenas refugiadas (Ruiz-Trejo y Ramazzini, 2021).

Walda Barrios-Klee tiene una extensa obra publicada, no obstante, en este texto quiero enfocarme en los artículos que publicó en la Revista Ámbar, una de las publicaciones independientes que marcó toda una época en el periodismo combativo en Chiapas de los años ochenta (s. XX) y en donde encontré varios textos publicados por ella. Uno de ellos fue "La situación de las mujeres en el socialismo" (1988) que escribió desde la República Democrática Alemana, en donde permaneció durante diez meses, en sus años de exilio. Dicho trabajo es el resultado de su interacción con mujeres de distintos sectores sociales: obreras, intelectuales, estudiantes, amas de casa, entre otras. Walda muestra sus impresiones sobre un estado joven, fundado en 1949, en el que según su apreciación:

"las mujeres gozan en la RDA de los mismos derechos que los hombres (...): tiene el derecho al trabajo y cualquier posibilidad de ascenso y capacitación; tiene el derecho de decidir cuántos hijos desean tener y cuándo; tiene el derecho de casarse, divorciarse o quedarse sola con o sin hijos sin perder el status social. Estas mujeres ya no dependen de los hombres, ni por el aprecio de la sociedad, ni por el apoyo económico de estos. El sistema de guarderías estatales es uno de los más amplios del mundo" (Barrios, 1988: 58). 
El artículo es un trabajo de tipo etnográfico en el que plasma las observaciones que hace en las calles principales de Berlín, en una fábrica de confección de abrigos en donde la mayoría de las trabajadoras son mujeres. Ofrece cifras de quienes realizaban oficios y de las que cursaban estudios superiores, de las condiciones de trabajo y de lo que implicaba la intensificación integral de la producción en el socialismo de la RDA: "la construcción del socialismo implica la consolidación de una fuerte economía y para ello se requiere trabajo y productividad", "las mujeres trabajan en todas las ramas y esferas de la economía” (Barrios, 1988, p. 58).

También explica "conquistas en la historia de Alemania": la situación de las mujeres en el campo, quienes tenían títulos profesionales; la formación de Cooperativas de Producción Agropecuaria; la capacitación de las mujeres en el agro, el uso de métodos con tecnología moderna y los horarios establecidos, las vacaciones anuales, las licencias pre y post natal pagadas, entre otros logros de la RDA, que tenían las campesinas. Así también habla de las bajas cifras de mujeres que prefieren quedarse en casa; de las estudiantes con doctorado, de las jefas y directoras de empresa, de las jubiladas y de las mujeres desempleadas que recibían una renta.

De acuerdo con las conversaciones que Walda tuvo con varias mujeres de la RDA, pudo registrar que el cambio, por las exigencias a una sociedad socialista, se logró más en la "esfera social pública", que en la esfera social privada", debido a que las mujeres aún tenían que librar pequeñas batallas domésticas para que sus compañeros compartieran con ellas las obligaciones que implica el hogar y la convivencia en común. Algo que llama la atención es que Walda utilizaba las herramientas de la etnografía de manera cuidadosa, tal como escribe en el mismo artículo con referencia a las mujeres del estado socialista ubicado en el centro de Europa:

"todas ellas dispuestas a compartir, sus experiencias, de esa forma pusieron en mis manos retazos de su vida, en un acto de confianza. A todas esas personas nunca las podré olvidar porque la confianza es el primer acto de amor, y en esa forma facilitaron no sólo mi quehacer académico (por no decir científico) sino que hicieron más grata mi estancia en la RDA" (Barrios 1988: 58).

Así también mencionó que a los hombres todavía les costaba enfrentarse a ver a sus compañeras como iguales, algo que atribuyó a los "siglos de patriarcado" y a un "problema social y psicológico". Walda terminó dicho artículo con una idea inminente: "Podemos confiar en que los esfuerzos de nuestras luchas no serán en vano, cuando exista la voluntad de construir verdaderamente una sociedad mejor para todos" (Barrios 1988: 60).

También encontré otros tres artículos que escribió en la misma revista con los siguientes títulos: "Las mujeres en China” (1989a), “Las mujeres en China II” (1989b), "Las mujeres en China III” (1989c), "Arribo a Beijing” (1989d), así como "China: diez años de reforma y apertura” (1989e). En ellos, escribió sobre su arribo a Beijing y su paso por la China socialista y campesina, que le sirvió para comparar las similitudes y las diferencias entre aquel país y América Latina, así como para ver todos los problemas que implica una transición a una sociedad socialista y los retos no sólo personales, sino colectivos que hay que hacer para lograr cambios. Así se preguntó:

“¿cómo triunfa una revolución?, ¿cómo es posible llegar a ese estado en que nadie pasa hambre, por falta de abrigo? El triunfo de una revolución sólo es posible cuando esta es una verdadera revolución popular. Ello significa el involucramiento de las masas, la superación del espíritu de las sectas. La participación de todos, hasta del más insignificante simpatizante, sintiéndose todos parte de un movimiento global, que será de esta forma capaz de gestar una nueva sociedad. La revolución china fue una revolución inminentemente popular. Y hoy día, en las calles, en todo el ambiente, se respira al pueblo chino. Ese ser campesino, producto de una cultura milenaria, que no ha perdido la ingenuidad, el don de paz y de darse a los demás.” (Barrios, 1989a: 11). 
Por otro lado, Walda Barrios utilizó herramientas de la antropología con perspectiva de género para desmitificar la representación sobre la opresión milenaria de las mujeres orientales que dominaba los imaginarios de la época. La misma autora señala que no puede negar el hecho de que las mujeres orientales han sido marginadas durante un periodo largo de la historia. No obstante, Walda apuntó a que esta situación no ha sido privativa del Oriente, sino una cuestión recurrente en distintas culturas en las que el régimen patriarcal permeó.

En el mismo artículo (1989a), la antropóloga guatemalteca explicó que las prácticas particulares de la sociedad china, tales como vendar los pies a las mujeres, eran manifestaciones opresivas que se dieron también en Europa, pero de otras maneras, por ejemplo, con la cosificación que vivieron las mujeres, así como el hecho de no poseer autonomía, primero bajo la férrea tutela del padre, después bajo la del marido. Esta observación demuestra que ya desde aquella época, Walda Barrios tenía un pensamiento complejo posicionado desde una postura descolonizadora, lejana de la antropología etnocéntrica dominante. En ocasiones, el etnocentrismo ha producido que la antropología juzgue las formas culturales de otras comunidades y de otros grupos de mujeres, según las propias normas y juicios de las culturas de los antropólogos. Walda Barrios, desmarcándose de esta postura, señaló: "Esta opresión no ha sido ni más ni menos en Occidente que en Oriente, pero el fenómeno adquiere distintas formas de manifestación, pero en esencia es básicamente el mismo" (Barrios, 1989a: 8).

Varios de los números revisados de la misma revista dan cuenta de las escasas plumas de mujeres en estos medios independientes. No obstante, las pocas mujeres que aparecían como autoras, se convirtieron después en figuras importantes de la antropología feminista en la región: Aída Hernández, Xochitl Leyva, María Teresa Paz Salinas y las integrantes del Grupo de Mujeres de San Cristóbal de las Casas, quienes llegaron a hacer denuncias sobre violencia sexual hacia niñas y adolescentes en la época ${ }^{20}$. Escribían también varias plumas, hoy consolidadas en la antropología en Chiapas como: Andrés Aubry, Antonio García de León, Antonio Mosquera, Andrés Fábregas, entre otros ${ }^{21}$.

En Chiapas, Walda Barrios-Klee es recordada por su labor en la creación del Taller "Antzetik" (mujer en tsotsil) que, en 1984, reunió en San Cristóbal de las Casas, a mujeres universitarias, urbanas, campesinas y guatemaltecas refugiadas en México (Ruiz-Trejo, 2020a). Dicho taller surgió como un espacio contra la violencia sexual hacia las mujeres y fue un lugar de encuentro de investigadoras y activistas que discutían y luchaban en los movimientos sociales en contra de la penalización del aborto y hacían trabajo de difusión sobre VIH. Walda también fue editora en San Cristóbal de las Casas, Chiapas, una revista feminista con el mismo nombre del taller "Antzetik", y cuyos análisis son otra de las líneas de investigación abiertas.

En el año 2000, Walda volvió a Guatemala y posteriormente terminó sus estudios de doctorado en sociología de la Universidad Pontificia de Salamanca, en su programa de Guatemala. Luego, esta antropóloga guatemalteca tuvo una etapa muy intensa de actividades en las que, por cuestiones de límites en la extensión de este trabajo, no me extenderé. Son muchas las etapas y aportes que hizo al estudio de la situación de las mujeres, a la antropología feminista y a las Ciencias Sociales y a las Humanidades en general. En este trabajo, he querido rendir homenaje a esta antropóloga feminista guatemalteca y luchadora centroamericana, a través de la revisión de tan solo algunos de sus artículos, posiblemente menos conocidos.

\footnotetext{
20 El Grupo de Mujeres de San Cristóbal denunció en 1989 que “En Chiapas no hay justicia para las mujeres” debido a que la mayoría de los acusados por casos de violencia contra las mujeres no llegaban siquiera a ser juzgados por negligencia y corrupción.

21 También colaboraban otros periodistas, escritores, intelectuales, fotógrafos e investigadores de otras disciplinas como: Juan Balboa, Miguel Álvarez del Toro, Eliane Casorla, Óscar Palacios, Samuel Ruiz García, Federico y Becky Álvarez del Toro, Leticia Hernández, Candelaria Rodríguez, Carlos Román García, Saúl López de la Torre, Jorge y Fredy López Arevalo, Marisa Trejo Sirvent, José Luis Ruiz Abreu, Carlos Uriel, Sergio Nicolás, José Ángel Rodríguez, Antonio Turok, entre otros.
} 
Hablar de Walda Barrios-Klee es aún difícil para mí, debido que ha sido una figura cuyo trabajo se entrecruzó con mis caminos desde la infancia, desde los Encuentros de Intelectuales Chiapas-Centroamérica, a finales de los ochenta y principios de los noventa. En 2016 y de nuevo en 2018, viajé a Guatemala con el fin de entrevistarla para mi investigación sobre la historia de las mujeres en Ciencias Sociales y en Humanidades, como una de las iniciadoras de los estudios de las mujeres y feministas en nuestra región. Desde aquel momento, Walda siempre estuvo presente en varios de mis proyectos que todavía resienten su ausencia. Hoy sus estudiantes de antropología y sociología son un legado vivo, memoria presente y lucha que trascenderá generaciones enteras en toda la región latinoamericana y caribeña.

\section{El racismo en las élites de poder en Guatemala en la obra de Marta Casaús}

La formación histórica de los grupos dominantes en América Latina ha sido un tema poco estudiado (Adler-Lomnitz, 1994; Adler-Lomniz y Pérez, 1987). Existen escasos trabajos que rastreen la historia de su conformación en la larga duración y existen aún menos investigaciones que indaguen en las orientaciones político-ideológicas en países como Guatemala. Las redes de parentesco, que sostienen las bases económicas de dichos grupos, en distintos momentos históricos fue el tema de investigación que realizó Marta Casaús Arzú, desde finales de la década de los setenta y durante los años ochenta (s. XX).

Marta Casaús nació el 24 de marzo de 1948, en Guatemala capital. Durante su infancia, vivió con sus abuelos Arturo Castillo y María Goubaud, propietarios y directivos de la cervecería centroamericana. Se crió en una de las familias más ricas de Guatemala. Su madre Odette Arzú Castillo estaba enlazada con dos grandes familias de élite y de corte nobiliario. La unión de esas familias configuró "redes familiares", estructuras de larga duración que utilizan la estrategia de relacionar la idea de "abolengo" con capital para acumular más poder económico (Casaús, 2007 [1992]). Marta proviene de una familia de la oligarquía guatemalteca, así como de una genealogía de mujeres fuertes, libres y valientes que desafiaron el androcentrismo de su época.

Durante su niñez vivió en un ambiente de "burbuja", como ella mismo lo describió en una entrevista que le hice el 25 de septiembre de 2020. Constantemente la reprimían al jugar con niños indígenas, lo que marcó su infancia y la de su país como una historia de segregación y separación entre las familias que se consideraban "blancas” y familias indígenas. Posteriormente, Marta vivió en México y en España. Entre los 13 y 14 años, volvió a Guatemala y estudió en un colegio relativamente abierto. "Vivía como una niña de la clase dominante en un país de enorme pobreza, pero no era consciente de nada".

Fue hasta entrar a la Facultad de Ciencias Políticas, en la Universidad Complutense de Madrid, cuando comenzó a darse cuenta de las enormes brechas de desigualdad, gracias a la masa crítica en contra de la dictadura franquista que se encontró en la universidad. Ahí conoció a Teresa Giráldez, una de sus grandes aliadas, colegas y amigas, junto con quien se formó en el pensamiento gramsciano y participó en distintas luchas europeas de la época, como el bastión anti-franquista antidictatorial y el movimiento obrero italiano. Durante toda su carrera, participaron en distintas marchas y se enfrentaron con la policía. Según Casaús, "fue un momento de toma de conciencia".

En esos años su relación con Guatemala era distante, pero volvía frecuentemente a ver a su madre. Era una época no tanto de gobiernos dictatoriales, pero sí represivos. Se produjeron múltiples asesinatos selectivos por parte de grupos paramilitares como "La Mano Blanca" o el "Movimiento de Liberación Nacional”, organizaciones anti-comunistas. Así la historiadora me relató:

"Yo vivía aterrorizada porque la gente a la que yo podía ver [en Guatemala] era la gente de la élite de poder que estaba vinculada a todos estos grupos paramilitares. Para mi era chocante. A lo largo de la carrera cuando venía a Guatemala se me paraba el pelo, no entendía porque había ese maltrato contra las poblaciones indígenas. 
Entonces ahí empecé a tomar mucha conciencia y a trabajar con grupos guatemaltecos que ya colaboraban, todavía no con el movimiento revolucionario, pero sí que estaban muy vinculados a la oposición” (Entrevista a Marta Casaús Arzú, vía remota, 25 de septiembre de 2020).

En 1978, el ejército guatemalteco asesinó a grupos indígenas mayas q'eqchi' en lo que se conoce como la masacre de Panzós. A partir de este dramático evento, Casaús comenzó a involucrarse más en los movimientos sociales guatemaltecos y a interesarse por las luchas de los movimientos revolucionarios ${ }^{22}$. Por otra parte, sus mayores influencias fueron el pensamiento anticolonialista, a través de la obra de Fanon, Memmi y Césaire y siempre fue muy crítica con el marxismo, desde la invasión a Praga, Checoslovaquia, hasta las posiciones de la Unión Soviética de las que siempre se sintió lejana. De haber estado cercana de alguna corriente se habría sentido más próxima al anarquismo y al trostkismo que al marxismo ortodoxo²3.

El pensamiento de Antonio Gramsci, filósofo marxista italiano, influyó fuertemente en su obra, en la que se pueden identificar, al menos, cuatro nociones de manera transversal. La primera noción gramsciana se relaciona con la idea de intelectual orgánico como la persona que hace de intermediario entre las diferentes capas o clases en un momento determinado y el que asegura a su grupo, clase o red, el control y la pervivencia como clase dominante. El segundo termino es el de núcleo oligárquico o bloque en el poder, en el sentido de que cada clase o grupo tiene a lo largo de la historia un núcleo oligárquico o clase fundamental, que es la que le asegura al resto su mantenimiento en el bloque de poder y le permite seguir controlando el poder político y económico a través del intelectual orgánico. El tercer término claramente gramsciano en su obra es el concepto de ideología como concepción del mundo de una clase determinada y no como falsa conciencia.

Así también utiliza la noción de hegemonía político-cultural como la pugna producida entre las diversas capas o grupos de la clase dominante en el conflicto ideológico por la preservación del poder y cómo, dentro del núcleo oligárquico y en el espacio de la sociedad política, se producen estas pugnas por la hegemonía político-cultural, lo que permite a un grupo u otro, tener, conservar o perder la hegemonía al interior del bloque histórico. Para Casaús, la gran diferencia entre un análisis gramsciano y otro marxista tradicional u ortodoxo es la gran flexibilidad y el análisis más sutil y menos mecánico y simple. Por ello, su libro Guatemala: Linaje y racismo (2007 [1992]) ha pervivido durante tanto tiempo, debido al análisis de redes y por el concepto de hegemonía y bloque en el poder.

Las experiencias ambivalentes de observar el racismo profundo de la clase dominante y la desigualdad extrema en Guatemala la impulsaron a centrar su tesis en estas problemáticas. En un principio, su pregunta era “ ¿por quéla sociedad guatemalteca no incluye a los indígenas?”. Este planteamiento no se orientaba tanto a la noción de racismo, sin embargo, esto cambió en el momento en que, entre 1979 y 1989, realizó una encuesta entre las veintidós familias con mayor poder de Guatemala, aquellas que concentraban la mayor riqueza y dominio político y social, pero también el mayor número de redes interfamiliares. Uno de sus hallazgos fue que muchas de dichas familias realizaban ciertos matrimonios para acumular más poder.

\footnotetext{
22 En la época en la que Casaús realizó su investigación había dos organizaciones revolucionarias: el Ejército Guerrillero de los Pobres (EGP)y Organización Revolucionaria del Pueblo en Armas (ORPA) y cada una tenía su propia filosofía. El EGP tenía una postura más marxista-lenininista y ORPA tenía una fuerte influencia del pensamiento gramsciano.

23 ORPA estaba más influenciado por autores anticoloniales como Carlos Guzman Böclker y Jean-Loup Herbert, por el pensamiento francés, por la guerra de Argelia, por Jean Paul Sartre y Camille Claudel. En cambio, el EGP tenía más cercanía con al marxismo, el pensamiento de los estados y de las nacionalidades y tenía una noción más centralista. Había muchas diferencias ideológicas sobre quién era el sujeto histórico fundamental del proceso revolucionario. Para el EGP seguía siendo el campesinado desde un análisis de clase y para las Fuerzas Armadas Revolucionarias (FAR) seguía siendo el proletariado. En cambio, para ORPA, el sujeto histórico eran los pueblos o comunidades indígenas y el proceso de liberación consistía en combatir el racismo y la discriminación.
} 
Otro de sus hallazgos radicó en la demostración de que el racismo opera como una ideología que se extiende a todo el grupo social dominante. Al preguntarles por su adscripción étnica (“¿usted qué se considera?", "razone su respuesta” o “ ¿cree usted que tiene algo de sangre indígena?”), una gran mayoría de los individuos entrevistados respondieron que se consideraban blancos y criollos, ninguno se consideró indígena, y muy pocos mestizos o ladinos. Los entrevistados con estudios de nivel superior negaron de manera más rotunda poseer sangre indígena y fueron los que tenían solo estudios de primaria quienes consideraban que sí tenían sangre indígena. De esta manera, el trabajo de Casaús reveló que en la auto-identificación y en la adscripción étnica es en donde empieza a operar el principio discriminatorio hacia los pueblos indígenas, por considerarse "biológicamente blancos puros y sin mezcla de sangre".

Una gran mayoría se consideraban blancos, debido a su supuestamente ascendencia española o europea. En las representaciones sobre sus antepasados lejanos europeos, estos son los que les conferían la identidad como blancos. Incluso algunos de ellos llegaron a mostrar "pruebas" como los "certificados de pureza de sangre", en donde supuestamente demostraban poseer el grupo sanguíneo "o" negativo, como prueba de su supuesta ascendencia vasca y de la ausencia de mestizaje, argumentos que Casaús describe como "evidentemente falsos, ya que las 'razas' no existen, fueron un invento del siglo XIX para controlar poblaciones, pero lo que sí existe es el racismo biológico".

En el estudio realizado por Casaús (2007 [1992]), en los años ochenta, la noción de pigmentocracia apareció como un elemento importante para describir la ideología de la clase dominante. Esta se entiende como prejuicio étnico elaborado por las élites blancas que controlan el poder y los medios de comunicación y que construyen un discurso racista. La pigmentación de la piel y la pureza de sangre es una obsesión y un elemento significativo y reiterativo en las familias de las élites, entrevistadas por Casaús, y esta noción aparece a lo largo de varios siglos en sus discursos y prácticas y se reproducen, entre otras formas, a través de las obras de distintos intelectuales, pertenecientes a dichas familias.

Casaús (2007 [1992]) también llegó a preguntar a los individuos de las élites de poder: “¿qué hubiera sucedido de no haber llegado los españoles, ni ningún otro pueblo europeo, a colonizar Guatemala?”. Una gran parte de los entrevistados respondieron que se habría producido un desarrollo diferente, menor o más lento, y que Guatemala se encontraría en un tremendo atraso. "Estaríamos subidos a los árboles" o "estaríamos en un estado de total salvajismo". Otro imaginario que predominó en el estudio es que una ventaja de la conquista fue la "mejora de la raza".

Los y las entrevistadas por Casaús identificaron con distintos adjetivos negativos para caracterizar a los indígenas, muchos de ellos relacionados con los rasgos físicos. Uno de los hallazgos de Casaús (2007 [1992]) fue observar cómo dichos prejuicios étnicos y de clase están directamente relacionados con la posición de clase de la oligarquía y con la explotación y opresión que ejercen sobre los pueblos indígenas. Así en las opiniones de los entrevistados, los pueblos indígenas y negros son considerados como grupos inferiores, lo que para Casaús (2007 [1992]) constituye un ejercicio recurrente en todas las relaciones de producción y de discriminación en todos los niveles: económico, político, social y cultural. Algunos entrevistados propusieron no solamente la integración o ladinización de los pueblos indígenas, sino su total exterminio, lo que para Casaús resultó inquietante y alarmante. Estos hallazgos de años de investigación sirvieron para validar el peritaje que presentó en 2014 en el juicio por genocidio y por los delitos contra los deberes de la humanidad perpetrados contra el pueblo maya ixil en los años ochenta en Guatemala. En dicho juicio, liderado por la fiscal general y jefa del Ministerio Público Claudia Paz y Paz, el Tribunal de Alto Riesgo condenó al general Efraín Ríos Montt a 80 años de cárcel. 


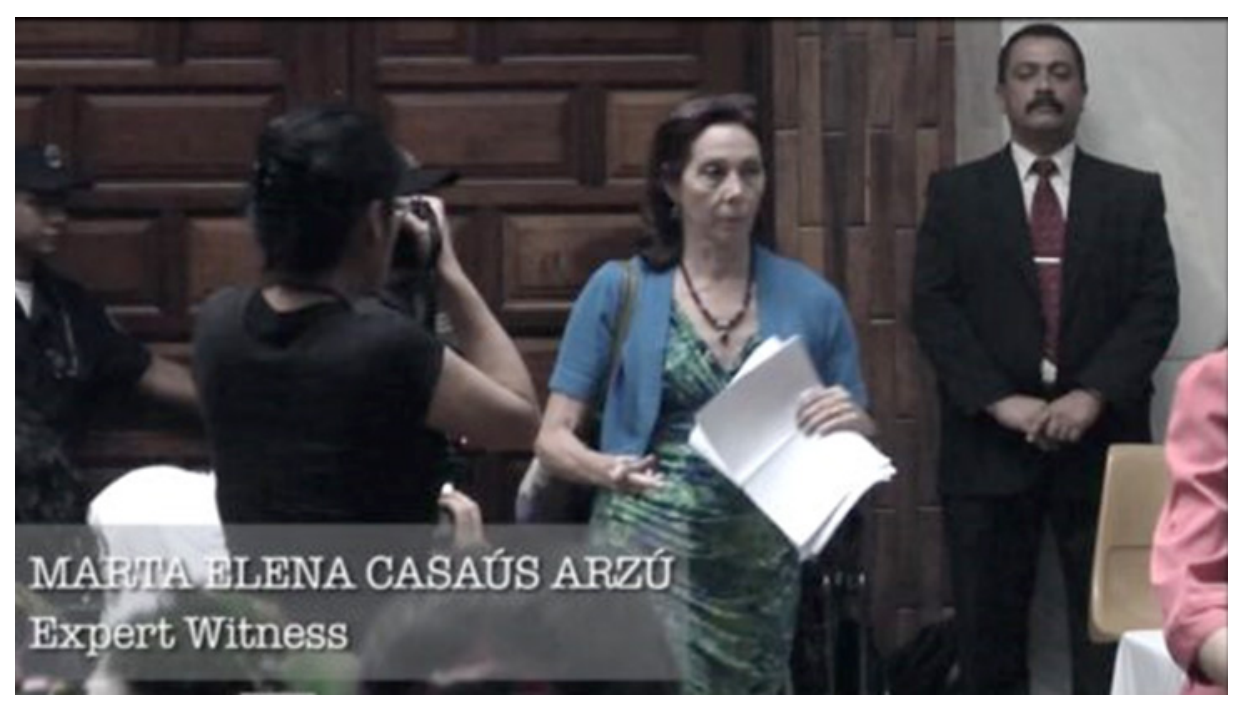

Marta Casaús entrando a la sala del Tribunal de Mayor Riesgo para presentar su peritaje en el juicio por genocidio contra Efraín Rios Montt (2013). Imagen del documental “El Veredicto", Pamela Yates, Skylight.

Durante el juicio, la fotografía de Marta Casaús fue exhibida como "terrorista" por su participación como perito, junto a los rostros de varias personas que hicieron posible el juicio histórico, tales como Yassmin Barrios, Claudia Paz y Paz y Rigoberta Menchú, entre otras mujeres valientes. Las fotografías exponían sus rostros de forma similiar a las imágenes de desaparecidos durante los años del conflicto interno armado en Guatemala, por lo que representaron amenazas frontales de muerte (Ruiz-Trejo, 2016).

En el año 2016, algunas mujeres q'eqchi' dieron sus testimonios en el juicio del "Caso Sepur-Zarco". En este juicio sin precedentes, la violación sexual se reconoció como un arma de guerra, que afectó tanto a las mujeres q'eqchi' como a los varones, ya que fue una agresión al grupo considerado "contrario" y tuvo como fin su exterminio (Casaús y Ruiz-Trejo, 2017). El trabajo forzado, la esclavitud y la violación sexual de las mujeres fueron diseñados como tácticas y estrategias para el control de los territorios e implicaron gastos para el ejército (armas, agentes para utilizarlas, etcétera).

En dicho juicio, Marta Casaús Arzú, presentó un peritaje histórico-antropológico (Casaús y Ruiz Trejo, 2017), para ofrecer una interpretación de los hechos. Tuve la oportunidad de colaborar con ella en la elaboración de dicho peritaje en el que explicamos cómo operó la protocolización de las violaciones, las políticas eugenésicas, mezcladas con el racismo de la élite y oligarquía militar, así como con la misoginia y la asociación del cuerpo de las mujeres con la posesión de los territorios. Se sentenció a dos exmilitares por 360 años. Sin duda, los testimonios de las mujeres q'eqchi', que levantaron su voz y contaron sus experiencias, fueron verdades innegables.

Durante muchos años, Marta Casaús fue profesora de Historia de América por la Universidad Autónoma de Madrid, de donde es profesora emérita, en donde fundó el Máster Europeo en Estudios Latinoamericanos: Complejidad Social y Diversidad Cultural y un programa de doctorado, en donde yo me formé. Marta Casaús nunca se ha cansado de luchar. A sus estudiantes nos ha transmitido el interés por la investigación activista y comprometida. Sus teorizaciones y metodologías de investigación son un gran aporte para la antropología feminista al considerar no sólo el género como la opresión de las mujeres, sino también la etnicidad, la raza, la lengua, el color de piel, entre otras categorías, de manera multidimensional. Su trabajo es fundamental para 
analizar el pensamiento y las prácticas de las oligarquías en Centroamérica, para orientar hacia lo público las investigaciones a través de peritajes o políticas públicas contra el racismo y por la igualdad de derechos para todas las personas y para vincularlas con los activismos y la transformación social ${ }^{24}$.

\section{Reflexiones finales inconclusas}

En este artículo, analicé las vidas y obras de algunas mujeres rebeldes y revolucionarias, cuyos trabajos son importantes para la antropología feminista en la región. Mostré cómo sus vidas personales y su participación en los movimientos revolucionarios, sociales y feministas impactaron fuertemente en su producción epistémica, así como lo que implicó en términos académicos, teóricos y metodológicos, políticos, éticos y también personales.

Leer y conocer los trabajos de Alaíde Foppa, Stella Quan Rossell, Walda Barrios-Klee y Marta Casaús Arzú me ha permitido entender que corrientes teóricas como las críticas feministas marxistas, socialistas, el pensamiento gramsciano y anticolonial tuvieron fuerte influencia en varias de las pensadoras seleccionadas, tanto en sus trabajos académicos como en su activismo político en Chiapas y Centroamérica. Las lecturas de las obras de estas feministas marxistas, socialistas, gramscianas y anticolonialistas, así como el análisis del contexto de represión y de resistencia al que se enfrentaron, me hacen pensar que la antropología feminista en la región tiene un punto de enunciación alternativo al del contexto que vivieron las antropólogas blancas (no así las antropólogas afroamericanas) en Estados Unidos, quienes tuvieron más oportunidades y recursos en las universidades norteamericanas para desarrollar sus investigaciones y, sobre todo, no se enfrentaron a ejercer docencia y a realizar investigaciones en instituciones de educación superior en medio de conflictos armados como los centroamericanos. Los trabajos comprometidos y responsables de las antropólogas e investigadoras centroamericanas, en medio de riesgos, peligros y amenazas, caracterizan la sofisticación del aparato teórico y de la riqueza política feminista en Chiapas. y Centroamérica.

La revisión del material recogido me ha permitido observar que algunas investigadoras en esta región se dedicaron en gran medida al estudio de las experiencias de las mujeres, pero también de otros sujetos; que a diferencia de otros contextos, la antropología feminista en esta región surgió aunada a los movimientos revolucionarios centroamericanos y emergió vinculada a coyunturas políticas críticas, a la represión y desaparición de familiares o a los movimientos de desplazados internos y a reivindicaciones relacionadas con la reivindicación de los derechos más elementales, el derecho a la vida, a la verdad y a la justicia. Por ello, la antropología feminista en Chiapas y Centroamérica ha tenido un desarrollo particular, propio y crítico, tanto con relación a la antropología social androcéntrica como respecto de la antropología feminista anglosajona o francesa y sus dualismos moderno-coloniales.

La antropología feminista en Chiapas y Centroamérica se ha enfrentado también al largo proceso de "acuerdos de paz" y "posconflicto". Algunas de las mujeres y de las feministas que vivieron la represión en las décadas de los setenta y ochenta en Guatemala, El Salvador y Nicaragua se exiliaron en México, en donde después de sus agitados años de militancia revolucionaria se formaron en la Escuela Nacional de Antropología e Historia (ENAH). Durante su época de formación, algunas de ellas, publicaron textos con sus nombres reales, tal como Aura Marina Arriola, algo que no habían podido hacer en sus países de origen, sobre el pensamiento

24 Recientemente realizamos conjuntamente un seminario de investigación titulado "Memorias en las orillas: mujeres y feministas en las Ciencias Sociales en Chiapas y Centroamérica”, organizado en el marco de la Fundación María y Antonio Goubeau, de la cual Marta Casaús es directora y fundadora y en el que participaron distintas investigadoras y artistas indígenas, afrodescendientes y mestizas-ladinas comprometidas, cuyas participaciones se convirtieron en un libro sobre los aportes de estas pensadoras a las Ciencias Sociales en la región (Ruiz-Trejo, 202ob). http:||fundacionmag.org/index.php/actividades/ actividades-anteriores/memorias-en-las-orillas-mujeres-y-feministas-en-las-ciencias-sociales-en-chiapas-y-centroamerica/ 
crítico de las clases sociales en Centroamérica, en los que reflexionaron sobre las alianzas obrero-campesinas articuladas con movimientos ladino-indígenas o escribieron relatos autobiográficos. Algunas otras fueron desaparecidas o asesinadas, tal como el caso de Alaíde Foppa o de Myrna Mack.

Después de años, algunas exiliadas lograron retornar a sus lugares de origen donde, entre otros aportes, tuvieron la experiencia política de trabajar en los procesos de memoria histórica a través del acompañamiento para la recopilación de testimonios de mujeres sobrevivientes de violencia sexual durante el conflicto armado en Guatemala, Nicaragua y El Salvador, como es el caso de Walda Barrios, Yolanda Aguilar, entre otras. Los diálogos con algunas de las pensadoras de esa época me han hecho no perder de vista que el contexto de conflicto armado las hizo colaborar en los procesos de memoria, de justicia y de verdad.

El contexto proporcionó a las antropólogas e investigadoras sociales de la época una gama de posibilidades de entender la vida y de tomar conciencia de lo que significaba partir de las historias de guerra y de los conflictos armados. Estas historias produjeron no solo entendimientos desde otra perspectiva que no era solo la de la izquierda o la revolucionaria, sino una compresión diversificada de lo que significaba "ser mujeres", del cuerpo y la sexualidad y la perspectiva de género y feminista en antropología se abrió a una dimensión compleja diferente a la que se dio en otros contextos.

A lo largo de los años, las contribuciones de los movimientos feministas, el aumento de mujeres científicas y las críticas profundas a la ciencia han permitido ir construyendo una historia de la antropología hecha y escrita por mujeres y otros sujetos de la diversidad y de la disidencia. Debemos algunos de los logros y avances a antropólogas y pensadoras como las mencionadas en este trabajo.

El afianzamiento de las mujeres en las universidades en México y su participación en los programas de posgrado es aún insuficiente. Actualmente se desafía ese punto de vista retrogrado que aún considera que las mujeres no pueden hacer ciencia tan bien como los hombres privilegiados. Las Ciencias Sociales y las Humanidades feministas han cultivado la capacidad de respuesta en el presente para que los actos de violencia racista, genocida y de violencia contra las mujeres no se vuelvan a repetir.

Con mi trabajo, he querido contribuir a las genealogías de las antropologías feministas en la región chiapaneca y centroamericana, para las que aún hacen falta más teorizaciones, así como análisis antropológicos sobre los feminismos de distintas generaciones, sus cambios, logros y articulaciones. Mi trabajo ha pretendido entender los aportes de las antropólogas y pensadoras feministas marxistas, socialistas, gramscianas y anticoloniales para dimensionar su importancia, aunque será necesario seguir profundizando en cada una de las etapas y periodos, diferenciar cada uno de los países y regiones, para que la vida, la obra y el compromiso de las mujeres y de las feministas diversas se sigan conociendo y multiplicando. Su esfuerzo no ha sido en vano y el hecho de poder escribir este trabajo es una expresión de su legado.

Recebido: 27 de julio de 2021

Aprobado: og de septiembre 2021 


\section{Bibliografía}

ADLER-LOMNITZ, Larissa. 1994. Redes sociales, cultura y poder. Ensayos de antropología latinoamericana. Ciudad de México: FLACSO. Disponible en: https://www.flacso.edu.mx/sites/default/files/libros_oa/redessociales.pdf

ADLER-LOMNITZ, Larissa; PÉREZ, Marisol. 1987. A Mexican Elite Family. 1820-1980: Kinship, class and culture. Princeton, New Jersey: Princeton University Press.

BARRIOS, Walda. 1988. “La situación de las mujeres en el socialismo”. Ámbar semanal, 7: 58-60.

BARRIOS, Walda. 1989a. "Mujeres de China, Ámbar semanal, 1(16): 8.

BARRIOS, Walda. 1989b. "Mujeres de China (II)", Ámbar semanal, 1(25): 11.

BARRIOS, Walda. 1989c. "Mujeres de China (III)", Ámbar semanal, 1(12): 11.

BARRIOS, Walda. 1989d. "Arribo a Beijing”, Ámbar semanal, 1(12): 11.

BARRIOS, Walda 1989e. "China: diez años de reforma y apertura”, Ámbar semanal, 1(8): 4.

BERRIO, Lina; CASTAÑEDA, Martha Patricia; GOLDSMITH, Mary; RUIZ-TREJO,

Marisa; SALAS, Monserrat; VALLADARES, Laura (coords.). 2020. Antropologías feministas en México: epistemologías, éticas, prácticas y miradas diversas. Ciudad de México: Universidad Autónoma Metropolitana-Ixtapalapa; Universidad Autónoma Metropolitana-Xochimilco; Universidad Nacional Autónoma de México y Bonilla Arteagas Editorial.

CASAÚS, Marta. 2007 [1992]. Guatemala: Linaje y racismo. Ciudad de Guatemala: F\&G Editores.

CASAÚS, Marta y RUIZ-TREJO, Marisa. 2017. “Procesos de justicia y reparación: el caso 'Sepur Zarco' por violencia sexual, violación y esclavitud doméstica en Guatemala y su sentencia paradigmática para la jurisprudencia internacional", Pacarina del Sur, 8 (30), enero-marzo, Disponible en: https:||www. academia.edu/31136716/Procesos_de_justicia_y_reparación_el_caso_Sepur_Zarco_por_violencia_ sexual_violación_y_esclavitud_doméstica_en_Guatemala_y_su_sentencia_paradigmática_para_la_ jurisprudencia_internacional_2017_

CASTAÑEDA, Patricia. 2012. "Antropólogas y feministas: apuntes acerca de las iniciadoras de la antropología feminista en México". Cuadernos de Antropología Social, 36: 33-49. Disponible en: https:/| www.redalyc.org/articulo.oa?id=180926074003

CASTAÑEDA, Patricia. 2015. "Etnógrafas feministas en la antropología mexicana: acercamientos para la elaboración de una genealogía disciplinaria”. In: J. Chávez (org.), Perspectiva de género. Una mirada de universitarias. México: ENTS-UNAM. pp. 119-141.

ENGELS, Friedrich [1884], 1970. El origen de la familia, la propiedad privada y el estado. Madrid. Fundamentos.

DALLA COSTA, Mariarosa; SELMA, James. 1975. El Poder de La Mujer y La Subversión de La Comunidad. México: Siglo XXI.

FOPPA, Alaíde. 1977.“¿Salario para el trabajo doméstico?”. Fem, i(3): 13-17.

GOLDSMITH, Mary; SÁNCHEZ, Martha Judith. 2014. "Las mujeres en la época de oro de la antropología mexicana: 1935-1965." Mora, 20: 121-135.

LARGUÍA, Isabel; DUMOULIN, John. 1976. Hacia una ciencia de la liberación de la mujer/Por un feminismo científico. Barcelona: Cuadernos de Anagrama.

MARTÍN, Aurelia. 2006. Antropología del género. Culturas, mitos y estereotipos sexuales. Madrid: Ediciones Cátedra, Universidad de Valencia.

MÉNDEZ, Liz. 2018. “Tríptico de la revolución”. Azacuán, texto audiovisual. Disponible en: https://azacuan. com/entrevista/triptico-de-la-revolucion-por-stella-quan/?fbclid=IwAR1SuJ7y5AY-kNKJ-5Gmx S3X70BrB81Ff5Rmog6QWg92WNkN555a7_fW1Y).

MOSQUERA, Antonio. 2021. “Con su patria en el corazón”. Prensa Libre, 9 de mayo. Disponible en: https:/| www.prensalibre.com/opinion/columnasdiarias/con-su-patria-en-el-corazon/ Acesado: August 1st, 2021 
NAVARRETE, Yosahandi. 2020. "Alaíde Foppa y AIMUR, o una voz que emerge en medio de las llamas".

GaZeta. Disponible en: https:||gazeta.gt/alaide-foppa-y-aimur-o-una-voz-que-emerge-en-medio-de-lasllamas/Acesado en 1 de agosto de 2021

QUAN, Stella 1972. Guatemala: una cultura de la ignominia Siete biografías y una entrevista. Maestría en Etnología, Escuela Nacional de Antropología e Historia (ENAH), Ciudad de México. Disponible en: https:||mx.antropotesis.alterum.info|?p=171

QUAN, Stella. 1981. "Por la vida de la compañera Alaíde Foppa”. Revista Fem, 4, 17, 83-84.

QUAN, Stella.1982. "Esta noche esta carta, Alaíde”. Revista Fem, 5, 20, 54-55.

QUAN, Stella. 1983. "El norte”, dirigida por Gregory Nava (Estados Unidos, Reino Unido, Drama, Thriller). Aventuras. Disponible en: https://mubi.com/es/films/el-norte

QUAN, Stella. 1984. “Our Daily Bread”. En: R. Morgan (comp.), Sisterhood is global. The international Women's Movement Anthology. New York: Open Road. pp. 281-285.

QUAN, Stella. 2018a. La Escuela Nacional de Bellas Artes y los escritores y artistas del 44.Jacobo Rodríguez Padilla: una historia de vida. Guatemala: Catafixia Editorial.

QUAN, Stella. 2018b. La semilla que yo sembré. Alfonso Solórzano: testimonio. Guatemala: Catafixia Editorial.

QUAN, Stella. 2018c. No es el fin. Es el mar: crónica y voces de Luis Cardoza y Aragón. Guatemala: Catafixia Editorial.

RUIZ-TREJO, Marisa. 2016. "Aproximaciones a los estudios críticos feministas de las ciencias sociales en México y Centroamérica”. Revista Clepsydra: Revista de Estudios de Género y Teoría Feminista, 15: 11-34.

RUIZ-TREJO, Marisa. 2020a. "Acercamientos a las antropologías feministas en Chiapas y Centroamérica". En: L. Berrio et al. (comp.), Antropologías feministas en México: epistemologías, éticas, prácticas y miradas diversas. México: UNAM, UAM-X y UAM-I. 83-119.

RUIZ-TREJO, Marisa. 2020b. Descolonizar y despatriarcalizar las Ciencias Sociales, la memoria y la vida en Chiapas, Centroamérica y el Caribe. Tuxtla Gutiérrez: Universidad Autónoma de Chiapas.

RUIZ-TREJO, Marisa y RAMAZZINI, Ana Lucía. 2021. “In memoriam: Walda Barrios-Klee (1951-2021)". Lasa Forum: 52: 3, 58-61.

RUIZ-TREJO, Marisa. 2022. "Dos pioneras en antropología en Chiapas y Guatemala". LiminaR Estudios Sociales y Humanisticas, CESMECA-UNICACH, XX(1). 20 (1), pp. 1-23.

RODRÍGUEZ DE ITA, Guadalupe 2020. "Exiliados guatemaltecos en México: Una experiencia recurrente". Pacarina del Sur, 12 (45), octubre-diciembre. Disponible en: http://pacarinadelsur.com/home/abordajes-ycontiendas/319-exiliados-guatemaltecos-en-mexico-una-experiencia-recurrente

SOLÓRZANO, Julio. 2021. "Memoria de su familia. Los que fueron muertos y desaparecidos y los que sobrevivieron". Memorial para la concordia, verdad, memoria, justicia y paz. Guatemala. Disponible en: http:/|memorialparalaconcordia.org/?page_id=2678

Marisa Ruiz Trejo

Universidad Autónoma de Chiapas

Profesora/investigadora de la Maestría en Estudios sobre Diversidad Cultural y Espacios Sociales https://orcid.org/0000-0003-4012-5601

Email: marisaruiztrejo@unach.mx 